\title{
Do Commodities Herd? Evidence from a Time-Varying Stochastic Volatility Model
}

\author{
Vassilios Babalos ${ }^{1}$, Stavros Stavroyiannis $^{2}$, Rangan Gupta $^{3}$
}

\begin{abstract}
Commodities markets due to their unique characteristics as diversification tools have recently garnered investors' attention especially through the development of commodity index financial products. This financialization process that started in the early 2000s and escalated after 2004 has precipitated price comovements among various types of commodities creating a proper setting for the examination of herding behavior. Employing a comprehensive dataset of investable commodities indices we examine the existence of herding behavior via static and time varying models. Our findings reveal a non significant anti herding behavior according to static model that is reversed when time varying models are in place. In particular the rolling window analysis reveals interesting patterns of the herding phenomenon. These behavioral patterns are corroborated through a time varying stochastic volatility model. Our results contain significant implications for investors, commodities producers and policy makers.
\end{abstract}

Keywords: commodities; herding; time varying stochastic volatility

JEL Classifications: Q02

\footnotetext{
${ }^{1}$ Corresponding author. Department of Accounting \& Finance, Technological Educational Institute of Peloponnese; Department of Banking \& Financial Management, University of Piraeus, Greece. Email:vbabalos@teikal.gr.

${ }^{2}$ Department of Accounting \& Finance, Technological Educational Institute of Peloponnese, Greece. Email: stavroyian@teikal.gr.

3 Department of Economics, University of Pretoria, Pretoria, 0002, South Africa. Email: Rangan.Gupta@up.ac.za.
} 


\section{Introduction}

Commodities have recently been in the epicenter of a heated debate by researchers and academics because of their growing size, their use as hedging against inflation, and their historically low correlation with traditional assets such as stocks and bonds. During early 2000s the belief that commodities were in the doorstep of a new super era was gaining prominence among academics (Radetzki, 2006) and among investors (Heap, 2005). Thus following a prolonged period of economic expansion of developing countries such as BRICS commodity prices marked a substantial surge in the late 2000s reaching a peak in early 2011. However, this situation was shortly reversed following markets' fears about the fragile economic recovery. Commodities are treated as a separate asset class (Daskalaki \& Skiadopoulos, 2011) exhibiting distinctive features compared to stocks and bonds. On the supply side, prices of many agricultural commodities are weather sensitive while regional conflicts in the Ukraine or Middle East and North Africa have fueled sizeable variability in gas and oil price respectively. On the other hand the outburst of the global financial crisis (GFC) that hurt the industrial production and the subsequent need for raw materials coupled with the weaker Chinese economic growth have ratified a period of weak demand for commodities. Commodities growing popularity has been further amplified by the bursting of the late 2000s US 'internet bubble' and the recent global financial and the ensuing sovereign debt crises. Thus, investors that suffer losses in their stock or bond portfolios turn their attention to alternative asset classes that wear the name of safe heavens against market-wide shocks such as gold (Baur \& McDermott, 2010).

Over the last decades commodities markets have become strongly integrated with traditional financial markets. The reasons behind this financialization of 
commodities markets are mainly focused on the extensive use of commodities as diversification and hedging tool by financial investors. In other words, commodities have caught the attention of numerous institutional investors as a profitable alternative asset. Another related issue that might contribute to the financialization and increased variability of commodities markets is the onset of a new type of market participant namely financial index investors. For example, food commodity prices have registered an upward trend and marked multiple large peaks since 2006, the most noteworthy in 2007-2008. Upon the entry of financial index investors in the commodities futures markets a substantial portion of researchers' attention has been directed towards trading behavior of this group of investors. It is natural to expect that a large scale buying pressure stemming from financial index traders gives rise to a number of massive bubbles in agricultural futures prices. However, this assertion lacks empirical support since relevant studies fail to establish a direct link between index trading and agricultural futures pricing (Irwin and Sanders, 2011). Commodities financialization leaves room for noise trading and momentum strategies that in turn might exaggerate price increases. In light of the above trading strategies the explosive growth of commodity prices in the period from 2005 to 2008 has been placed under scrutiny. Behavioral-based explanations are often put forward by researchers (Etienne et al., 2014) in their attempt to justify these unprecedented levels of commodities prices.

Prior research on herding behavior maps its way into two different strands. On the one hand there are studies that investigate group-wide herding formally defined as synchronized actions among institutional investors or certain groups of investors, such as mutual fund managers or financial analysts. These studies usually rely on a transaction-based herding model that requires detailed records on the trading behavior 
(buy/sell actions) of specific group of investors. Lakonishok et al. (1992) in their influential study introduced what was destined to become a widely employed transaction-based herding measure. Their analysis was conducted for a sample of US pension fund managers and documented no significant pattern in managers' trading actions. Related studies include among others Frey et al. (2014), Jiao \& Ye (2014), Kremer \& Nautz (2013), Clement and Tse (2005), Gleason et al. (2003), Graham (1999), Trueman (1994), Welch (2000), and Wermers (1999). Still, the majority of the relevant studies explores the formation of herding patterns by measuring the shifts of stock returns dispersion in response to market movements. The theoretical foundations of this test were put forward by Christie and Huang (1995) who claimed that herding reveals itself as a market-wide phenomenon causing a common response of asset prices irrespective of available information. Therefore, Christie and Huang (1995) pointed out that whenever cross-sectional dispersion in individual stock returns diminishes herding is detected. On the other hand, when cross-sectional dispersion of stock returns increases we observe the so-called anti-herding behavior. A growing number of studies have employed the above measures in order to explore herding effects in the US stock market (Christie \& Huang, 1995) and in an international setting as well. In particular Chiang et al. (2010), Demirer and Kutan (2006), Tan et al. (2008), investigated the existence of herding effects in the Chinese stock markets whereas Chiang and Zheng (2010) examined a large sample of 18 markets. In a related study, Gleason et al. (2004) examined herding in the US market by employing data on nine sector S\&P 500 Exchange Traded Funds (ETFs) listed on the American Stock Exchange. In the same vein Economou et al. (2011) documented herding behavior for four south European markets whereas Zhou \& Anderson (2013) and Philippas et al. (2013) examined the formation of herding behavior in the US REITs 
market. Recently, Mobarek et al. (2014) reported herding in the European stock indices during market crises while Galariotis et al. (2014) attempted to explain the herding behavior of US \& UK leading stocks using macroeconomic variables. Yao et al. (2014) found that Chinese markets A \& B exhibit different levels of herding behavior. Finally, employing an augmented version of Hwang \& Salmon (2004) herding model Messis \& Zapranis (2014) confirmed the existence of herding behavior in five developed stock markets. Stavroyiannis \& Babalos (2015) documented significant herding behavior of major European stock market indices that was dependent not only on the selected markets, but also on the time period under consideration.

Herding in commodity markets has received less attention compared to stock markets with the relevant studies reaching contradictory results. On the one hand, according to Pindyck and Rotemberg (1990) aligned trading behavior may give rise to intense comovements among commodity prices. Wiener (2006) in his study of speculative behavior in the international oil market concluded that herding might be present among specific subgroups of investors. Along the same lines, Gilbert (2009) documented some evidence of excessive behavior in non-ferrous metals markets that is driven by speculators' actions and dissipates quickly. Demirer et al. (2013) employing data on various commodities sectors report significant evidence of herd behavior only for grains. However, evidence against herding in commodity markets was provided by Chunrong et al. (2006). Adrangi and Chatrath (2008) relying on trading data documented that investors tended to follow each other but their actions do not qualify as herding behavior. Likewise, Boyd et al. (2009) employing trading data reported that the correlated actions of hedge fund managers do not pose a menace to the crude oil market. Steen and Gjolberg (2013) report no significant evidence in 
favor of herding and Pierdzioch et al. $(2010,2013)$ reported significant evidence of forecaster anti-herding behavior in oil and metals markets. More recently, Babalos \& Stavroyiannis (2015) employing a rolling window analysis documented anti-herding behaviour before the global financial crisis and the absence of herding or anti-herding behaviour during the crisis for a sample of metals commodities futures.

This article compliments studies on the debating issue of the formation of behavioral-based patterns in the rapidly growing market of the commodities futures. Employing an extensive and updated dataset from 2002 to the end of 2014, the time varying nature of herding and anti-herding transitions patterns are examined through static and time varying methods. Static models fail to capture the dynamic nature of such behaviors; structural break tests confirm our suspicions for possible shifts and non linearities in the relationship of the employed variables. Therefore, a rolling window of 400 observations is used, which is consistent with the peak to trough business cycle reference dates, December 2007-June 2009, given by the National Bureau of Economic Research (NBER) for the duration of the Global Financial Crisis. Realizing that rolling window estimations could be sensitive to window-sizes, we complement the analysis using a pure time-varying regression model with stochastic volatility. In many cases, data-generating process of economic variables seems to have drifting coefficients, as well as, shocks of stochastic volatility. If this happens to be the case, then coefficients of the time-varying model with constant volatility causes the estimated time-varying coefficients to be biased, since possible variation of the volatility in disturbances is ignored (Nakajima, 2011). To avoid this misspecification, stochastic volatility is assumed in the time varying regression model. Although stochastic volatility makes the estimation difficult because the likelihood function becomes intractable, the model can be estimated using Markov Chain Monte Carlo 
(MCMC) methods in the context of a Bayesian inference. Further note that, unlike the rolling window regressions, the time-varying approach ensures that the entire sample period is analyzed in a time-varying fashion, without compromising the initial window. In general, the time varying regressions corroborate the findings from the rolling regressions. Specifically, the results indicate statistically significant transitions between herding and anti-herding behavior in the commodities futures markets.

Previewing our results the estimates of the static CAPM-based herding model reveal an insignificant anti-herding behavior a finding that paves the way towards the use of a more informative, time-varying method. Motivated by substantial evidence of multiple structural breaks in the relationship of our variables as reflected in the values of proper tests we set off to employ a rolling window analysis that yields a more reliable assessment of the evolution of herding behavior. Most interestingly, significant instances of anti-herding behavior before the global financial crisis, and a statistically significant herding behavior as the window passes through the GFC period are reported. Finally, the results of the time-varying stochastic volatility model provide further support to the rolling window analysis.

The remainder of the paper is structured as follows. Section 2 outlines the data and the econometric methodology while Section 3 provides the results and the relevant discussion. Finally concluding remarks are discussed in Section 4.

\section{Data and econometric methodology}

\subsection{The data}

The dataset under examination includes the investable subindices of Standard \& Poor's Goldman Sachs Commodity Index (GSCI) that consist of the most liquid commodity futures on 25 different commodities sectors. In particular we employ 6 
futures indices from the Energy sector (Crude Oil, Unleaded Gasoline, Heating Oil, Gas Oil, Natural Gas, and Brent Crude Oil), 8 from the Metal sector (Aluminum, Copper, Gold, Platinum, Silver, Zinc, Lead, and Nickel), and 11 from the Agricultural sector (Cocoa, Coffee, Corn, Cotton, Grain, Lean Hog, Soya Beans, Sugar, Wheat, Feeder Cattle, and Live Cattle). The dataset consists of 3256 observations from 7January-2002, when the Feeder Cattle futures index was launched, to 31-December2014 obtained from Bloomberg. The returns are calculated via the sequential difference of the natural logarithm of the closing prices of the relevant indices, $R_{t}=\ln \left(P_{t} / P_{t-1}\right) \times 100$, where $P_{t}$ denotes the value of the index at time $t$, and in case of unavailable data due to national holidays, bank holidays, or any other reasons, the previous day closing price was used.

\subsection{Static herding model}

For the quantification of herding a measure of dispersion is needed. There are two alternative measures of dispersion in the literature, the cross-sectional standard deviation (CSSD) used in Christie and Huang (1995),

$\operatorname{CSSD}_{t}=\sqrt{\frac{\sum_{i=1}^{N}\left(R_{i, t}-R_{m, t}\right)^{2}}{N-1}}$

where $R_{i, t}$ is the return of the $i$-th asset at time t, and $R_{m, t}$ is the average of the $R_{i, t}$, and the

CSAD measure provided by Chang et al. (2000), hereinafter called CCK, defined as,

$$
C S A D_{t}=\frac{1}{N} \sum_{i=1}^{N}\left|R_{i, t}-R_{m, t}\right| \text {. }
$$

A significant difference is that the CSSD definition, calculated by squared returndeviations, might be sensitive and considerably affected by the existence of outliers. 
Both dispersion models are used to identify any possible herding behavior and provide an easily utilized approach applied on the market information. The conditional CAPM model, under normal circumstances, specifies a linear relationship between CSAD and market returns. Following this assumption, during period of market stress, if herding occurs a nonlinear relationship will also exist, which can be modeled as,

$$
C S A D_{t}=a_{0}+a_{1}\left|R_{m, t}\right|+a_{2} R_{m, t}^{2}+\varepsilon_{t}
$$

If herding is present, then $\mathrm{a}_{2}$ will be statistically significant and negative, implying that the deviation of returns contracts during periods of market stress.

We utilize the most commonly used measure of dispersion of returns in the literature, the CSAD measure, where the cross-sectional average return (CSAR) $R_{m, t}$ is realized as the value of an equally weighted average of the indices returns, and the Eq. (3) to quantify for any herding phenomena. In this study static analysis is enhanced by considering one-sided overlapping rolling window regression rolled by one day, to account for any dynamic properties of the herding phenomenon. For all regressions, static or rolled, estimated with the ordinary least squares (OLS) method, the statistical inference is based on Newey and West (1987) standard errors corrected for heteroskedasticity and serial correlation in the error terms.

\section{Empirical results}

\subsection{Descriptive statistics and stylized facts}

The stylized facts of the time series under consideration are reported in Table 1 where we report information on the annualized mean and standard deviation in percent, the skewness coefficient, the kurtosis coefficient, the Jarque-Bera (J.B.) normality test, the autoregressive conditional heteroskedasticity (ARCH) Lagrange 
multipliers (LM) test for heteroskedasticity, and the Ljung-Box (L.B.) test for serial correlation where the number of lags for the ARCH-LM and L.B. statistic to be tested was set to $10^{4}$. All series under consideration are leptokurtic with high kurtosis deviating from normality and negatively skewed, and except for Aluminum, Coffee, Corn, Wheat, Natural Gas, Cotton, Grain and Lean Hogs for the time interval under examination, the rest of the commodities have a positive mean. The J.B. test reveals the typical non-normality feature of the time series. The ARCH-LM test indicates the presence of heteroskedasticity, and the time series exhibit serial correlation according to the L.B. test statistic.

Table 1 Descriptive statistics and stylized facts

\begin{tabular}{|c|c|c|c|c|c|c|c|c|}
\hline Variable & $\begin{array}{c}\text { CRUDE } \\
\text { OIL }\end{array}$ & $\begin{array}{l}\text { UNLEADED } \\
\text { GASOLINE }\end{array}$ & $\begin{array}{c}\text { HEATING } \\
\text { OIL }\end{array}$ & ALUMINIUM & COCOA & COFFEE & COPPER & CORN \\
\hline Ann. Mean & $0.11 \%$ & $7.99 \%$ & $4.82 \%$ & $-1.53 \%$ & $4.18 \%$ & $-2.41 \%$ & $14.24 \%$ & $-4.38 \%$ \\
\hline Ann. Std.Dev & $34.11 \%$ & $35.86 \%$ & $32.25 \%$ & $22.73 \%$ & $29.99 \%$ & $32.41 \%$ & $29.03 \%$ & $29.15 \%$ \\
\hline Skewness & -0.238 & -0.224 & -0.063 & -0.316 & -0.329 & 0.181 & -0.147 & 0.060 \\
\hline Kurtosis & 3.14 & 2.46 & 1.84 & 2.27 & 2.76 & 2.17 & 3.99 & 1.86 \\
\hline J.B. & 1376.9 & 853.79 & 464.99 & 754.02 & 1100.4 & 662.04 & 2178 & 475.93 \\
\hline ARCH(10) & $73.59 * *$ & $57.73^{* *}$ & $41.76^{* *}$ & $20.24 * *$ & $8.46^{* *}$ & $10.64 * *$ & $68.77 * *$ & $25.26^{* *}$ \\
\hline LB(10) & $19.44^{*}$ & $22.69^{*}$ & 14.61 & 16.05 & 14.12 & 7.24 & $45.33^{* *}$ & 9.77 \\
\hline Variable & SILVER & $\begin{array}{c}\text { SOYA } \\
\text { BEANS } \\
\end{array}$ & SUGAR & WHEAT & ZINC & $\begin{array}{l}\text { GAS } \\
\text { OIL } \\
\end{array}$ & $\begin{array}{c}\text { NATURAL } \\
\text { GAS } \\
\end{array}$ & $\begin{array}{c}\text { BRENT } \\
\text { CRUDE } \\
\text { OIL } \\
\end{array}$ \\
\hline Ann. Mean & $8.40 \%$ & $11.94 \%$ & $0.00 \%$ & $-7.91 \%$ & $4.22 \%$ & $7.69 \%$ & $-30.59 \%$ & $6.55 \%$ \\
\hline Ann. Std.Dev & $34.24 \%$ & $25.34 \%$ & $32.73 \%$ & $32.36 \%$ & $32.05 \%$ & $29.41 \%$ & $47.88 \%$ & $31.36 \%$ \\
\hline Skewness & -0.934 & -0.230 & -0.297 & 0.060 & -0.198 & -0.012 & 0.210 & -0.199 \\
\hline Kurtosis & 6.76 & 1.89 & 2.13 & 1.73 & 2.47 & 2.1 & 1.95 & 3.25 \\
\hline J.B. & 6704.4 & 514.37 & 669.11 & 409.9 & 853.03 & 602.11 & 540.61 & 1462.4 \\
\hline $\operatorname{ARCH}(10)$ & $19.72 * *$ & $34.43 * *$ & $19.29 * *$ & $19.02 * *$ & $37.62 * *$ & $31.32 * *$ & $24.85^{* *}$ & $69.25^{* *}$ \\
\hline LB(10) & 9.08 & 9.6 & 12.64 & 3.48 & $23.33 * *$ & 13.11 & $53.97 * *$ & $28.52 * *$ \\
\hline Variable & COTTON & GOLD & GRAIN & LEAN HOGS & PLATINUM & LEAD & NICKEL & $\begin{array}{l}\text { FEEDER } \\
\text { CATTLE } \\
\end{array}$ \\
\hline Ann. Mean & $-4.23 \%$ & $10.42 \%$ & $-1.05 \%$ & $-11.87 \%$ & $8.74 \%$ & $10.72 \%$ & $9.08 \%$ & $4.45 \%$ \\
\hline Ann. Std.Dev & $28.30 \%$ & $19.26 \%$ & $25.35 \%$ & $23.20 \%$ & $22.62 \%$ & $35.01 \%$ & $38.53 \%$ & $14.03 \%$ \\
\hline Skewness & -0.093 & -0.431 & 0.000 & -0.075 & -0.632 & -0.235 & -0.151 & -0.270 \\
\hline Kurtosis & 1.1 & 4.91 & 1.97 & 0.89 & 4.08 & 3.14 & 3.36 & 1.45 \\
\hline J.B. & 169.2 & 3381.5 & 527.96 & 110.94 & 2483.3 & 1373.9 & 1547.8 & 323.37 \\
\hline $\operatorname{ARCH}(10)$ & $37.94 * *$ & $16.63^{* *}$ & $23.21 * *$ & $20.03 * *$ & $57.79 * *$ & $44.08 * *$ & $37.72 * *$ & $20.36^{* *}$ \\
\hline $\mathbf{L B}(10)$ & $23.85^{* *}$ & 12.87 & 5.43 & 11.98 & $22.89 *$ & $22.94 *$ & 6.36 & $52.84 * *$ \\
\hline
\end{tabular}

\footnotetext{
${ }^{4}$ The lag selection was based on Akaike criterion
} 


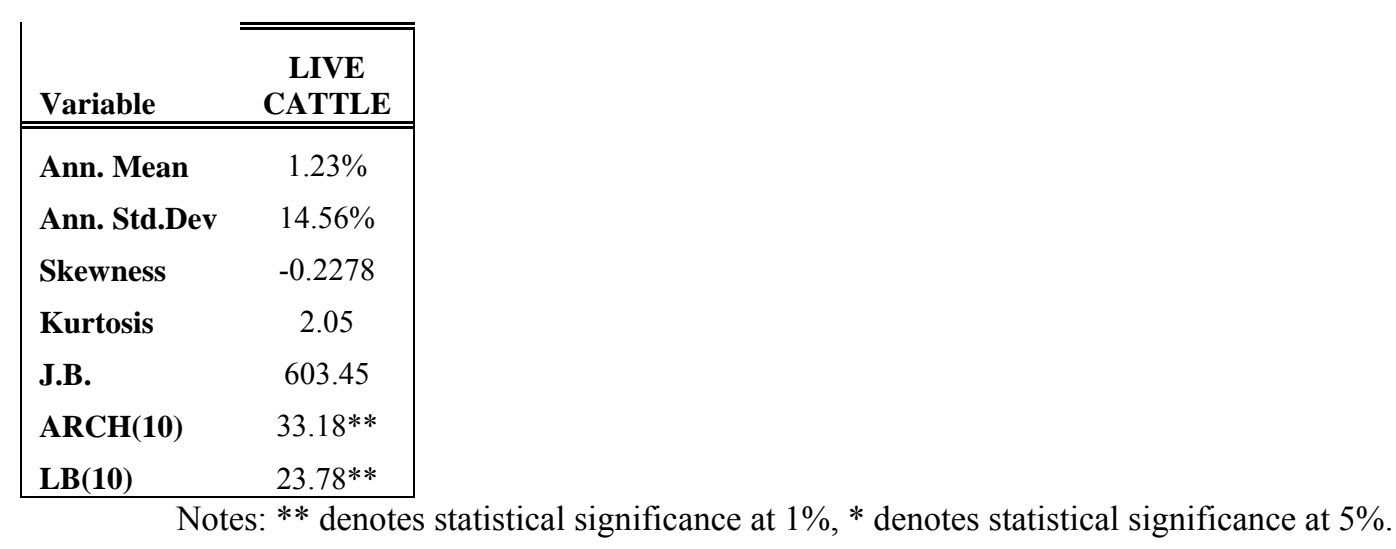

\subsection{Herding and anti-herding behavior in the commodity futures market}

Applying the nonlinear model of Eq. (3) the obtained coefficients for the commodity futures market, indicating a non-significant anti-herding behavior for the sample are,

$$
C S A D_{t}=0.0099+0.2571\left|R_{m, t}\right|+0.8793 R_{m, t}^{2}
$$

The above finding contradicts that of Demirer et al. (2013) who reported substantial evidence of anti-herding behavior for commodities markets, which brings into account the sensitivity of such static models to the time horizon under examination. Due to the fact that instances of anti-herding behavior have been reported, the usual null and alternative hypotheses in the herding literature have to be modified and reformulated as follows (Stavroyiannis and Babalos, 2015; Babalos and Stavroyiannis, 2015):

$\mathbf{H}_{\mathbf{0}}$. In the absence of herding effects we expect in the model $a_{1}>0$ and $a_{2}=0$.

$\mathbf{H}_{1}$. If herding effects are encountered we expect $a_{2}<0$; otherwise if $a_{2}>0$ antiherding behavior occurs. 


\subsection{Rolling Window Analysis of herding}

After examining the static CCK behavior for the whole sample, the more robust procedure of rolling window regression methodology is employed to assess the stability of the model's parameters and capture potential time-varying parameters. Our selection of time varying techniques is reinforced by strong evidence of nonlinearities (Brock et al., 1996 (BDS)) and structural breaks (Bai and Perron, 2003) that were detected in the residuals of equation (3), and equation (3) itself. In particular, the Bai and Perron (2003) test of multiple structural breaks identified possible structural shifts in the following dates of the sample: 14/1/2005, 7/11/2007, 20/10/2009 and $27 / 7 / 2012 .^{5}$ Also the BDS test indicated that the null hypothesis of serial dependence in the residuals for equation (3) is strongly rejected at $1 \%$ level of significance across various dimensions. At this point it is worth mentioning that only a few relevant studies account for possible time-varying parameters in the model's estimations. Therefore a line of criticism rests on the static character of the traditional methods that can be found in the seminal studies of Christie and Huang (1995) and Chang et al. (2000). These tests fail to explicitly accommodate the dynamic nature of the observed pattern. Along these lines and following the suggestions of Hwang and Salomon (2004) current research on the field has focused on a time-varying measure of herding. A few recent studies regarding dynamic approaches are by Balcilar et al., (2013, 2014) who used the regime switching approach, Gębka and Wohar (2013) using quantile regressions, and Klein (2013) uses Markov switching seemingly unrelated regressions. Since the values of the coefficients in the static model are sensitive to the selected sample period, it is necessary to carefully consider possible variations in the estimation results by shifting the sample period. Although the

\footnotetext{
${ }^{5}$ The Andrews (1993) and Andrews and Ploberger (1994) tests of structural instability applied to equation (3) also indicated evidence of structural instability.
} 
model's parameters are assumed to be constant over time in the time series analysis, this assumption may not be true, because the economic and financial environment often changes. A crisis or a structural break could render classic OLS estimates insufficient providing no information -regarding the dynamics of the system near or after the break. If the parameters are truly constant over the entire sample, then we should expect no significant variation of the estimates over the rolling windows. However, if the model parameters do exhibit time variation, then the rolling estimates should accommodate this instability and assess the model's stability. The size of the rolling window is related to the timescales of the system (response times), and the aim of the research (Su \& Huang, 2009), and since there is no golden rule for the right size of the rolling window, there is a trade-off between having a long enough window to estimate the metrics, and short enough to have a sufficient number of windows in order to be able to derive a trend. For systems with fast timescales short windows can be appropriate, whereas systems with slow timescales require longer rolling windows for the metrics to be able to capture changes in the signature of the time series. Short rolling windows may lead to irregular trends in the estimates of the metrics whereas long rolling windows smooth out the trends, and the shorter the rolling window is, the less accurate the estimate of the metric becomes.

Since we are interested in the behavior of the dataset during the recent global financial crisis we use a rolling window of 400 observations which is very close to the December 2007-June 2009 peak to trough business cycle reference dates given by the National Bureau of Economic Research (NBER) for the duration of the Global Financial Crisis (GFC). The results are plotted in Fig. 1 for the $a_{1}$ coefficient (top, left), the $a_{2}$ coefficient (top, right), the $5 \%$ t-statistic of the $a_{1}$ coefficient (bottom, left), and the $5 \%$ t-statistic for the $\mathrm{a}_{2}$ coefficient (bottom, right), where the first point in 
every subfigure is assigned to the end of the rolling window. We observe statistically significant instances of anti-herding behavior before the global financial crisis, and a statistically significant herding behavior as the window passes through the GFC period. Most interestingly the price bubble experienced by a wide range of commodities during 2008 is reflected in a statistically significant negative $\mathrm{a}_{2}$ coefficient that points to herding behavior.

Our time varying results are in line with those reported by Pierdzioch et al. (2010) and Pierdzioch et al. (2013) who detected evidence of anti-herding behavior among oil and metal price forecasters. In particular, according to Pierdzioch et al. (2013) the anti-herding behavior was attributed to a tendency among forecasters to spread forecasts around market forecast.
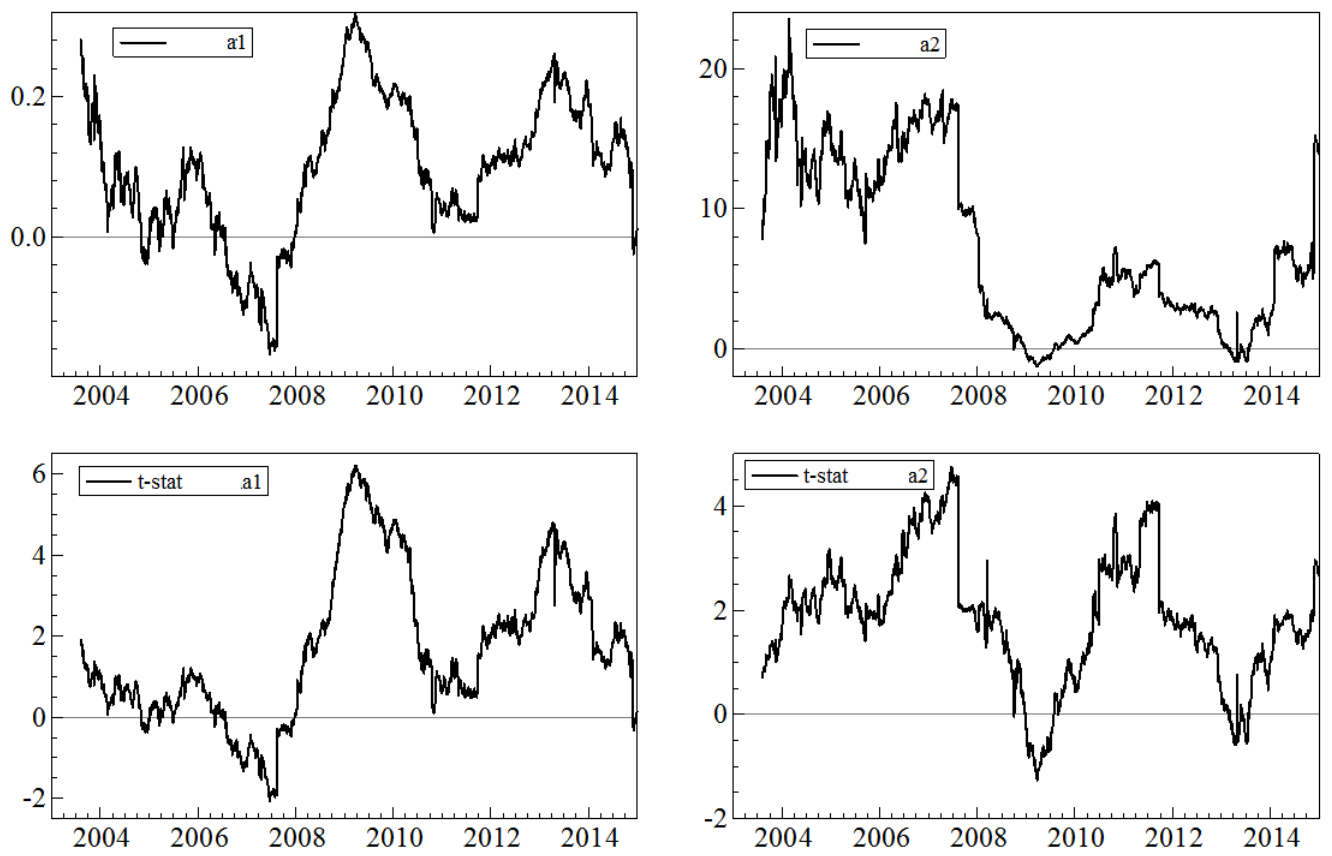

Fig. 1 Rolling window regression results showing the time evolution of the $a_{1}$ coefficient (top, left), the $a_{2}$ coefficient (top, right) and the t-statistics for the $a_{1}$ (bottom, left) and $a_{2}$ (bottom, right).

\subsection{Time-varying parameter VAR model with stochastic volatility}


The time-varying parameter regression model used in this work was proposed by Nakajima (2011). The model assumes that the time-varying coefficients follow a first order random walk process which allows for both temporary and permanent shifts in the coefficients. The drifting coefficient is meant to capture a possible nonlinearity, such as a gradual change or a structural break. To avoid the situation that the time-varying coefficients might capture some spurious movements as well, an AR(1) process might be incorporated with the persistence parameter less than one for stationarity. However, a structural change or a permanent shift of the coefficient would be difficult to estimate even if it exists. The model is given by:

$$
\begin{aligned}
& y_{t}=z_{t}^{\prime} a_{t}+\varepsilon_{t}, \varepsilon_{t} \sim N\left(0, \sigma_{t}^{2}\right), t=1, \ldots, n \\
& a_{t+1}=a_{t}+u_{t}, u_{t} \sim N(0, \Sigma), t=0, \ldots, n-1
\end{aligned}
$$

and stochastic volatility, $\sigma_{t}^{2}=\gamma \exp \left(h_{t}\right)$

$$
h_{t+1}=\phi h_{t}+\eta_{t}, \eta_{t} \sim N\left(0, \sigma_{\eta}^{2}\right), t=0, \ldots, n-1
$$

where $y_{t}$ is a scalar of response; $z_{t}$ is a $p \times 1$ vector of covariates that in our case consists of $\mathrm{R}_{\mathrm{m}}$ and $\mathrm{R}_{\mathrm{m}}^{2}$; $a_{t}$ is a $p \times 1$ vector of time-varying coefficients, and; $h_{t}$ is stochastic volatility. We assume that $|\phi|<1$ for the stationarity of the volatility process (7), $\Sigma$ is the positive-definite matrix, $\gamma>0, a_{0}=0, u_{0} \sim N\left(0, \Sigma_{0}\right), h_{0}=0$, and $\eta_{0} \sim N\left(0, \sigma_{\eta}^{2} /\left(1-\phi^{2}\right)\right)$. To reduce the computational burden in repeating the filtering many times for the evaluation of the likelihood function for each set of the parameters, the TVP regression model assumes a Bayesian approach using the Markov Chain Monte Carlo (MCMC) for an efficient estimation. The priors used are as

$$
\text { follows: } \beta \sim N(0,10 \times I),
$$$$
\Sigma \sim I W(4,40 \times I),
$$

$$
a_{1} \sim N(0,10 \times I),
$$

$(\phi+1) / 2 \sim \operatorname{Beta}(20,1.5), \sigma_{\eta}^{2} \sim \operatorname{IG}(2,0.02), \gamma \sim I G(2,0.02)$, where, IW denotes the inverse Wishart distribution, IG denotes the inverse Gamma distribution, and 30000 iterations are used, after discarding the first 3000 samples as a burn-in period. The results are plotted in Figure 2 where the time evolutions of the $a_{1}$ coefficient (top), the $\mathrm{a}_{2}$ coefficient (middle), and the stochastic volatility $\sigma_{t}=\exp \left(h_{t} / 2\right)$ (bottom) are presented. 

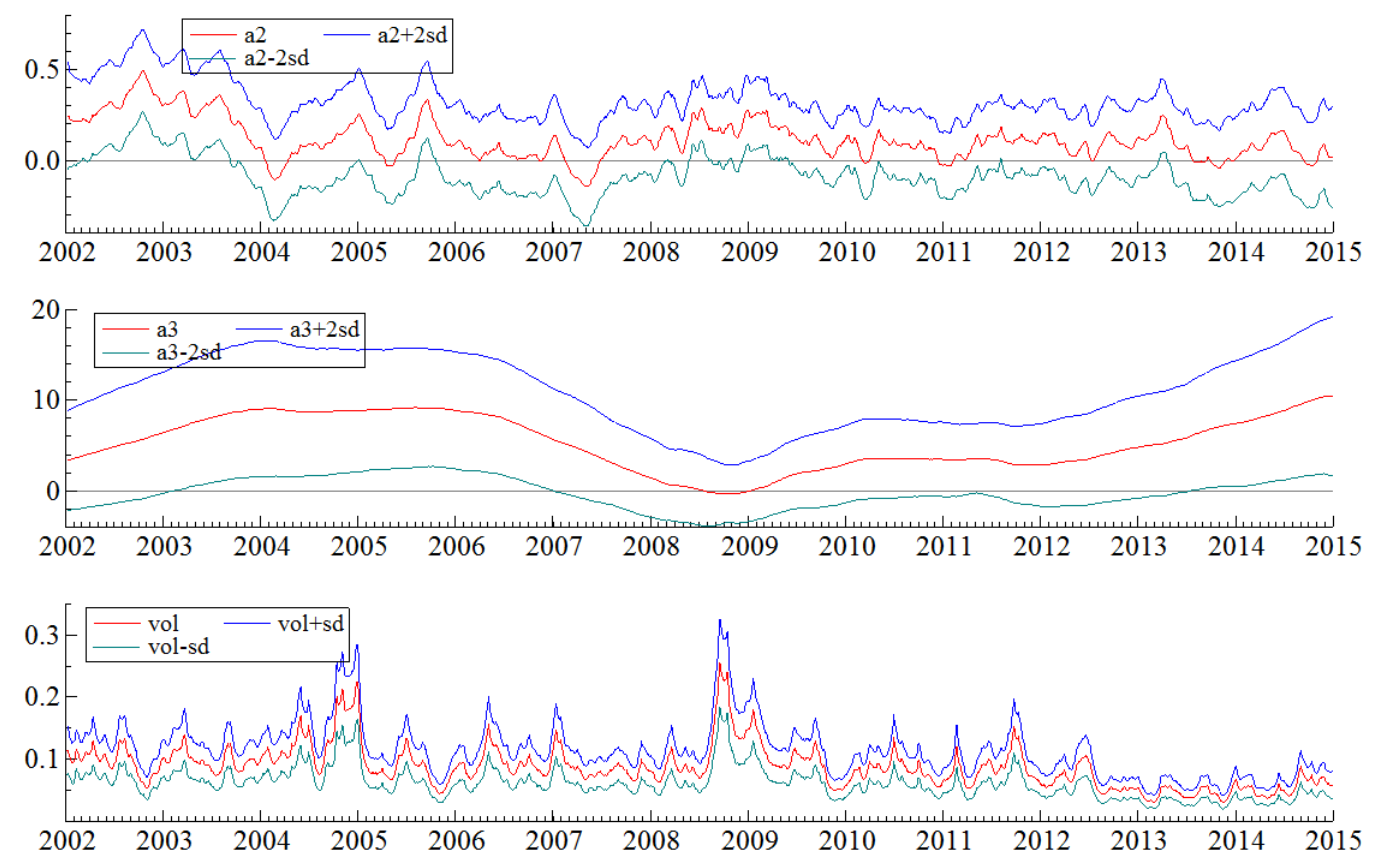

Fig. 2 Time evolution of the $a_{1}$ coefficient (top), the $a_{2}$ coefficient (middle), and the stochastic volatility $\sigma_{t}=\exp \left(h_{t} / 2\right)$ (bottom). The confidence levels are plus/minus two standard deviations for the coefficients and one standard deviation for the volatility.

Consistent with the rolling window results the value of the $\mathrm{a}_{2}$ coefficient has a small plunge during the financial crisis, at the second half of 2008, but remains at the positive level for the whole interval under examination. The autocorrelation functions for the parameters of the model are shown in Figure 3. If autocorrelation is still relatively high for higher values of lags this indicates high degree of correlation between the chains and slow mixing. The sample autocorrelations drop stably indicating that the sampling method produces samples with low autocorrelation. 

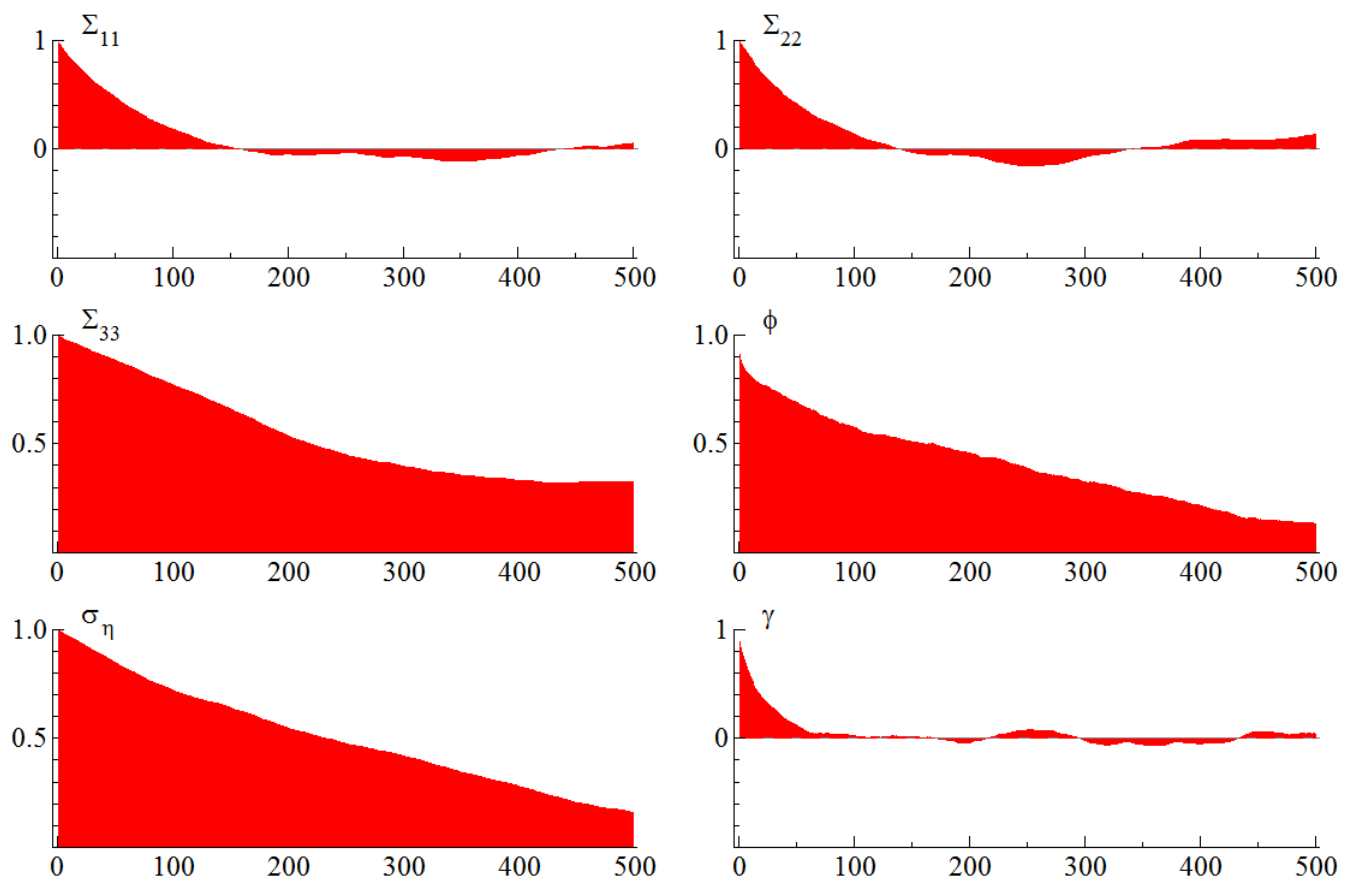

Fig. 3 Sample autocorrelation functions for the estimated parameters.

Table 2 reports the estimates for the posterior means, standard deviations, the $95 \%$ credible intervals, the convergence diagnostics (CD) of Geweke, and inefficiency factors, which are computed using the MCMC sample. The Geweke diagnostic takes two overlapping parts of the Markov chain and compares the means of the both parts using a difference of means test, to see if the two parts of the chain are from the same distribution, which is the null hypothesis. It is seen in the estimated results that the null hypothesis of convergence to the posterior distribution is not rejected for the parameters at the $5 \%$ significance level based on the $\mathrm{CD}$ statistics, and the inefficiency factors are quite low. For the $\Sigma_{33}$ the inefficiency factor is about 250 implying that we obtain 120 uncorrelated samples which are enough for the posterior inference.

Table 2: Convergence diagnostics

\begin{tabular}{lcccccc}
\hline \hline Parameter & Mean & Stdev & 95\%L & 95\%U & Geweke & Inef. \\
$\Sigma_{11}$ & 0.0007 & 0.0001 & 0.0005 & 0.0011 & 0.6670 & 94.41 \\
$\Sigma_{22}$ & 0.0008 & 0.0002 & 0.0005 & 0.0011 & 0.3720 & 84.70 \\
$\Sigma_{33}$ & 0.0498 & 0.0426 & 0.0042 & 0.1587 & 0.7030 & 331.05 \\
$\varphi$ & 0.9650 & 0.0135 & 0.9338 & 0.9850 & 0.2060 & 215.64 \\
$\sigma_{\mathrm{n}}$ & 0.1271 & 0.0276 & 0.0819 & 0.1824 & 0.1760 & 268.15 \\
$\gamma$ & 0.0775 & 0.0058 & 0.0663 & 0.0893 & 0.5090 & 45.58 \\
\hline
\end{tabular}


Notes: This table reports the posterior means, standard deviations, the $95 \%$ credible intervals, the convergence diagnostics (CD) of Geweke, and inefficiency factors, that are derived using the Markov Chain Monte Carlo (MCMC) sample.

\section{Conclusion}

This paper contributes to the literature exploring the formation of behavioralbased patterns in commodities futures markets. Commodities markets due to their unique characteristics as diversification tools have garnered investors' attention through the development of commodity index financial products. This tendency that started in the early 2000s and escalated after 2004 has precipitated price comovements among various types of commodities (see Tang \& Xiong, 2012) creating favorable conditions for the emergence of herding behavior.

Employing an extensive dataset of investable commodities futures indices from 2002 to 2014, standard testing procedures along with an overlapping rolling window regression and a novel time varying stochastic volatility model of Nakajima (2011) that capture any time-varying nature of the phenomenon were employed. For the commodities markets as a whole, both rolling window analysis and the robust time varying stochastic volatility model reveal statistically significant instances of antiherding behavior before the Global Financial Crisis and a statistically significant herding behavior during the Global Financial Crisis period. However, estimates of the static herding model point towards the existence of a non significant anti-herding pattern.

Our results entail significant implications for commodities markets' participants. In particular herding behavior and shifts in commodity price correlation carry important implications for a wide range of issues including commodity producers' hedging strategies and speculators' investment strategies to energy and 
food policies adopted by countries. It is natural to expect that these effects will be present considering that index-based financial products remain a salient feature of current investment strategies.

\section{References}

Adrangi, B., \& Chatrath, A. (2008). Do Commodity Traders Herd? The Financial Review 43, 461-476.

Aielli, G. P. (2013). Dynamic conditional correlations: on properties and estimation, Journal of Business and Economic Statistics, 31, 282-289.

Andrews, D. W. K. (1993) Tests for parameter instability and structural change with unknown change point, Econometrica, 61, 821-856

Andrews, Donald W. K. and W. Ploberger (1994). Optimal tests when a nuisance parameter is present only under the alternative," Econometrica, 62, 1383-1414.

Babalos, V., \& Stavroyiannis, S. (2015). Herding, anti-herding behaviour in metal commodities futures: a novel portfolio-based approach. Applied Economics, 47, $4952-4966$

Bai, Jushan and Pierre Perron (2003). Computation and analysis of multiple structural change models, Journal of Applied Econometrics, 6, 72-78. 
Balcilar, M., Demirer, R., \& Hammoudeh, S. (2013). Investor herds and regimeswitching: Evidence from Gulf Arab stock markets. Journal of International Financial Markets, Institutions and Money, 23, 295- 321.

Balcilar, M., Demirer, R., \& Hammoudeh, S. (2014). What drives herding in oil-rich, developing stock markets? Relative roles of own volatility and global factors. North American Journal of Economics and Finance, 29, 418-440.

Baur, D.G., \& McDermott, T.K. (2010). Is gold a safe haven? International evidence. Journal of Banking and Finance 34, 1886-1898.

Boyd, N., Buyuksahin, B., Haigh, M. S., Harris, J. H. (2009). The Prevalence, Sources and Effects of Herding. CFTC Working Paper.

Brock, W., Dechert, D., Scheinkman, J. and LeBaron, B. (1996). A test for independence based on the correlation dimension. Econometric Reviews, 15, 197235.

Buyuksahin, B., \& Harris, J. H. (2011) .Do Speculators Drive Crude Oil Futures Prices? The Energy Journal, 32, 167-202.

Chang, E. C., Cheng, J. W., \& Khorana, A. (2000). An examination of herd behavior in equity markets: an international perspective. Journal of Banking and Finance, 24, $1651-1679$. 
Chiang, T. C., \& Zheng, D. (2010). An empirical analysis of herd behavior in global stock markets. Journal of Banking and Finance, 34, 1911-1921.

Chiang, T. C., Li, J., \& Tan, L. (2010). Empirical investigation of herding behavior in Chinese stock markets: Evidence from quantile regression analysis. Global Finance Journal, 21, 111-124.

Christie, W. G., \& Huang, R. D. (1995). Following the pied piper: do individual returns herd around the market?. Financial Analysts Journal, 51, 31-37.

Chunrong, A., Chatrah, A., \& Song, F. (2006). On The Comovement of Commodity Prices. American Journal of Agricultural Economics, 88, 574-588

Clement, M., \& Tse, S. (2005). Financial Analyst Characteristics and Herding Behavior in Forecasting. The Journal of Finance, 60, 307-341

Daskalaki, C., \& Skiadopoulos, G. (2011). Should investors include commodities in their portfolios after all? New evidence. Journal of Banking \& Finance, 35, 26062626.

Demirer, R., \& Kutan, A. M. (2006). Does herding behavior exist in Chinese stock markets? Journal of International Financial Markets, Institutions and Money, 16, 123142. 
Demirer, R., Kutan, A.M., \& Chen, C. (2010). Do investors herd in emerging stock markets?: Evidence from the Taiwanese market. Journal of Economic Behavior and Organization, 76, 283-295.

Demirer, R., Lee, H. T., \& Lien, D. (2013). Commodity Financialization and Herd Behavior in Commodity Futures Markets. Working Paper Series, The University of Texas at San Antonio, College of Business.

Economou, F., Kostakis, A., \& Philippas, N. (2011). Cross-country effects in herding behavior: Evidence from four South European Markets. Journal of International Financial Markets, Institutions and Money, 21, 443-460.

Engle, R. F. (2002). Dynamic conditional correlation: a simple class of multivariate generalized autoregressive conditional heteroskedasticity models. Journal of Business and Economic Statistics, 20, 339-350.

Engle, R. F., \& Granger, C. W. J. (1987). Co-integration and error correction: Representation, estimation and testing. Econometrica, 55, 251-276.

Etienne, X. L., Irwin, S. H., \& Garcia, P. (2014). Bubbles in food commodity markets: Four decades of evidence. Journal of International Money and Finance, 42, $129-155$

French, K., (1986). Detecting spot price forecasts in futures prices. Journal of Business, 59, S39-S54. 
Frey, S., Herbst, P., \& Walter, A. (2014). Measuring mutual fund herding - A structural approach, Journal of International Financial Markets, Institutions and Money, 32, 219-239.

Galariotis, E. C., Rong, W., \& Spyrou, S. (2015). Herding on fundamental information: A comparative study. Journal of Banking \& Finance, 50, 589-598.

Gębka B., \& Wohar, M. E. (2013). International herding: Does it differ across sectors?, Journal of International Financial Markets Institutions and Money, 23, 5584.

Gilbert, C. L. (2009). Commodity Speculation and Commodity Investment. Working paper No. 0820, Deparment of Economics, University of Trento.

Gilbert C. L. (2010a). Speculative influences on commodity futures prices 20062008. UNCTAD Discussion Paper, No. 197, March.

Gilbert CL (2010b). Commodity speculation and commodity investment. FAO Commodity Market Review 2009-2010:26-46.

Gleason, K. C., Lee, C.L., \& Mathur, I. (2003). Herding Behavior in European Futures Markets. Finance Letters, 1, 5-8. 
Gleason, K .C, Mathur I., \& Peterson, M. A. (2004). Analysis of intraday herding behavior among the sector ETFs. Journal of Empirical Finance, 11, 681-694.

Glosten, L. R., Jagannathan, R., \& Runkle, D. E. (1993). On the relation between the expected value and the volatility of the nominal excess return on stocks. The Journal of Finance, 48, 1779-1801.

Goodfellow, C., Bohl, M. T., \& Gębka, B. (2009). Together we invest? Individual and institutional investors' trading behaviour in Poland. International Review of Financial Analysis, 18, 212-221.

Graham, J. R. (1999). Herding among Investment Newsletters: Theory and Evidence. The Journal of Finance, 54, 237-268.

Heap, A. (2005). China - the engine of a commodities super cycle. Citygroup Global Markets Inc., Smith Barney.

Henker, J., Henker, T., \& Mitsios, A. (2006). Do investors herd intraday in Australian equities? International Journal of Managerial Finance, 2, 196-219.

Hwang, S., \& Salmon, M. (2004). Market stress and herding. Journal of Empirical Finance, 11, 585-616.

Irwin, S., \& Sanders, D. (2011). Index funds, financialization, and commodity futures markets. Applied Economic Perspectives and Policy, 33 , 1-31. 
Jiao, Y., \& Ye, P. (2014). Mutual fund herding in response to hedge fund herding and the impacts on stock prices. Journal of Banking \& Finance, 49, 131-148.

Klein, A. C. (2013). Time-variations in herding behavior: Evidence from a Markov switching SUR model. Journal of International Financial Markets Institutions and Money, 26, 291-304.

Kremer, S., \& Nautz, D. (2013). Short-term Herding of Institutional Traders: New Evidence from the German Stock Market. European Financial Management, 19, 730746.

Lakonishok, J., Shleifer, A., \& Vishny, R. W. (1992). The Impact of Institutional Trading on Stock Prices. Journal of Financial Economics, 32, 23-43.

Lambert, P., \& Laurent, S. (2000). Modelling skewness dynamics in series of financial data. Discussion Paper, Institut de Statistique, Louvain-la-Neuve.

Laurent, S., \& Peters, J. P. (2002). G@RCH 2.2, an Ox package for estimating and forecasting various ARCH models. Journal of Economic Surveys, 16, 447-485.

Laurent, S. (2009). Estimating and forecasting ARCH Models using G@RCH 6, Timberlake Consultants Limited: London. 
Messis, P., \& Zapranis, A. (2014). Herding towards Higher Moment CAPM, contagion of herding and macroeconomic shocks: Evidence from five major developed markets, Journal of Behavioral and Experimental Finance, 4, 1-13.

Mobarek, A., Mollah,S., \& Keasey, K. (2014). A cross-country analysis of herd behavior in Europe. Journal of International Financial Markets Institutions \& Money, $32,107-127$.

Nakajima, J. (2011). Time-Varying Parameter VAR Model with Stochastic Volatility: An Overview of Methodology and Empirical Applications. Monetary and Economic Studies, 29, 107-142.

Newey, W. K, West, K. D. (1987). A Simple, Positive Semi-definite, Heteroskedasticity and Autocorrelation Consistent Covariance Matrix. Econometrica, $55,703-708$.

Nöth, M., \& Weber, M. (2003). Information aggregation with random ordering: Cascades and overconfidence. Economic Journal, 113, 166-189.

Phillips, P. C. B. \& Yu, J. (2010). Dating the timeline of financial bubbles during the subprime crisis. Quantitative Economics, 2, 455-491.

Philippas, N., Economou, F., Babalos, V., \& Kostakis, A. (2013). Herding behavior in REITs: Novel tests and the role of financial crisis. International Review of Financial Analysis, 29, 166-174. 
Pindyck, R., Rotemberg, J., 1990. The excess co-movement of commodity prices. Economic Journal, 100, 1173-1189.

Pierdzioch, C., Rülke, J. C., \& Stadtmann, G. (2010). New evidence of anti-herding of oil-price forecasters. Energy Economics, 32, 1456-1459.

Pierdzioch, C., Rülke, J. C., \& Stadtmann, G. (2013). Forecasting metal prices: Do forecasters herd? Journal of Banking \& Finance, 37, 150-158.

Radetzki, M. (2006). The anatomy of three commodity booms. Resources Policy, 31(1): 56-64.

Stavroyiannis, S. \& Babalos, V., (2015). On the time varying nature of herding behaviour: evidence from major European indices. Global Business and Economics Review, 17, 298-309.

Steen, M., \& Gjolberg, O. (2013). Are commodity markets characterized by herd behaviour?. Applied Economics, 23, 79-90.

Su, Y., \& Hwang, J. S. (2009). A two-phase approach to estimating time-varying parameters in the Capital Asset Pricing Model. Journal of Applied Statistics, 36, 7989. 
Tan, L., Chiang, T. C., Mason, J. R., \& Nelling, E. (2008). Herding behavior in Chinese stock markets: An examination of A and B shares. Pacific-Basin Finance Journal, 16, 61-77.

Tang, K., Xiong, W. (2012). Index Investment and the Financialization of Commodities, Financial Analysts Journal, 68, 54-74.

Trueman, B. (1994). Analysts Forecasts and Herd Behavior. Review of Financial Studies, 7, 97-124.

Welch, I. (2000). Herding among security analysts. Journal of Financial Economics, 58, 369-396.

Wermers, R. (1999). Mutual Fund Herding and the Impact on Stock Prices. The Journal of Finance, 54, 581-622.

Wiener, R. J. (2006). Do Birds of a Feather Flock Together? Speculator Herding in the World Oil Market. Discussion paper No. 06-31. Resources for the Futures.

Yao, J., Ma, C., \& Peng, H. W. (2014). Investor herding behaviour of Chinese stock market, International Review of Economics \& Finance, 29, 12-29.

Zhou, J., Anderson, R. I. (2013). An empirical investigation of herding behavior in the US REIT market. The Journal of Real Estate Finance and Economics, 47, 83-108. 